\title{
COMPORTAMIENTO ELECTORAL EN EL QUINDÍO A PARTIR DE LA REFORMA POLÍTICA DE 2003.
}

\section{ELECTORAL BEHAVIOR IN QUINDÍO STATE AFTER THE POLITICAL AMENDMENT BILL 2003}

\author{
Jorge Iván Cuervo R. ${ }^{1}$ \\ Carlos Andrés Olano C. ${ }^{2}$
}

\begin{abstract}
This paper presents details of the elections in Quindio State after the political amendment bill 2003, and how this amendment bill has influenced on the electoral behavior of the Colombian political parties and political movements, during the 2006 and 2007 elections.

This work thoroughly shows details of the electoral behavior in every single municipality. The composition of the state councils and assembly is presented and how mayor's offices and governor's office are established. Finally, the presidential elections are examined.
\end{abstract}

\section{Resumen.}

Los autores de esta reflexión se ocupan en detalle de las elecciones en el Departamento del Quindío a partir de la reforma política del 2003 y cómo ésta impacta el comportamiento electoral de los partidos y movimientos políticos en las elecciones de 2006 y 2007.

A reglón seguido detalla el comportamiento electoral municipio por municipio, registrando la composición de concejos y de la asamblea departamental y como quedan configuradas las alcaldías y la gobernación del departamento y finalmente revisa las elecciones a presidente.

1 Abogado, Especialista en Derecho Público, Especialista en Política Social, Magíster en Políticas Públicas. Docente .investigador de la Facultad de Finanzas, Gobierno y $\mathrm{R}$ e I a c i o $n$ e $\mathrm{s}$ Internacionales de la Universidad Externado d e Colom bi a. Columnista de la Crónica del Quindío. jorge.cuervo@uexterna do.edu.co

2 Profesional en Finanzas, Gobierno y $R$ e I a c i o $n$ e $s$ Internacionales. A s i s t e n t e d e Investigación de la Facultad de Finanzas, Gobierno Relaciones Internacionales de la Universidad Externado de Colombia. 


\section{Introducción.}

La Constitución de 1991 puede entenderse, desde el punto de vista del funcionamiento del sistema político, como una apuesta por la apertura de la democracia partidista en la búsqueda de mejorar la representatividad y la legitimidad del régimen político. La sociedad política del Frente Nacional debería dar paso a una sociedad política más plural, en la que pudieran participar otras fuerzas políticas distintas de las tradicionales liberal y conservadora, especialmente nuevas fuerzas políticas que canalizaran otras expresiones que habían sido excluidas del juego político. Esta exclusión de terceras fuerzas fue presentada como una de las causas de la violencia política en Colombia (Pecaut, 1989), y de ahí la necesidad de recomponer las reglas de juego para deslegitimar el uso de la violencia y fortalecer la democracia.

Si bien la Constitución de 1991 no introdujo una reforma sustancial al sistema electoral colombiano (Rodríguez- Raga, 2002), la introducción de la circunscripción nacional para Senado buscaba generar los incentivos necesarios para que terceras fuerzas, especialmente minoritarias, pudieran tener representación nacional, sacando el debate electoral del cerrado círculo de las circunscripciones regionales dominadas por el clientelismo y el caudillismo regional, y abriéndolo al debate nacional. Si embargo, la capacidad de adaptación de los actores políticos a las nuevas reglas de juego institucionales, hicieron que los objetivos de la Constitución de 1991 se diluyeran, y fuera necesario una reforma política para enfrentar la atomización partidista y los personalismos caudillistas que caracterizaron el comportamiento político luego de la Constitución de 1991.

Durante los gobiernos de Samper y de Pastrana se planteó la necesidad de reformar a fondo el sistema electoral para introducir cambios en el comportamiento del sistema político, especialmente para corregir el déficit de representatividad de los partidos y la dificultad que tenían en canalizar las demandas sociales y traducirlas en políticas públicas (Valenzuela, 1999), lo que a la postre terminaba afectando la legitimidad del propio régimen político.

El acto legislativo No. 1 de 2003 se constituye en la más ambiciosa reforma a la sistema electoral y al sistema político en procura de fortalecer los partidos políticos, incentivar la cohesión y la coherencia

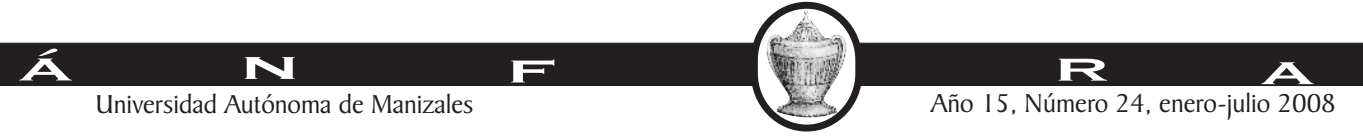


partidista y superar los problemas de representatividad política que habían sido inducidos por el comportamiento de los actores políticos con ocasión de las reformas introducidas en la Constitución de 1991 (Hoyos Gómez, 2007). El resultado de la reforma es aún preliminar, si bien se han logrado algunos de los objetivos iniciales, tales como reducir el número de partidos, incentivar la agrupación y la cohesión en el interior de los mismos -gracias entre otras razones el régimen de bancadas-, también es cierto que algunos de los problemas identificados siguen estando presentes, tales como la falta de representatividad, por razones relacionadas con el umbral y la cifra repartidora, el personalismo gracias al voto preferente, y la incapacidad de los partidos para evitar la influencia de actores armados ilegales que encuentra en la llamada parapolítica su más dramática expresión.

En este artículo se pretende hacer un balance de la reforma política al comportamiento electoral en el departamento del Quindío en las elecciones para gobernación, alcaldías, asamblea, concejos, cámara, senado y Presidente de la República, en los años 2002, 2003, y 2006 y 2007.

Una premisa de trabajo indica que en el Quindío, el impacto de la reforma política ha sido bastante marginal, por no decir nulo, como quiera que no ha habido una variación sustancial de la configuración política, la cual sigue gravitando alrededor de unos liderazgos regionales provenientes de los partidos tradicionales, los que se camuflan y desdoblan en nuevas franquicias políticas, con el agravante de que no han surgido nuevas formas de expresión regional verdaderamente significativas, salvo el movimiento político - religioso Mira. El déficit de representatividad del sistema político sigue siendo la constante en el Quindío. Para 2006, los senadores Mario Londoño (q.e.p.d) y Ricardo Arias, fueron elegidos con un total de 76.418 votos de los 156.150 votos válidos, lo que significa que, sumados los de los otros candidatos, cerca de de 60 mil votos fueron depositados por candidatos "foráneos". Si bien la circunscripción para Senado es de carácter nacional, la dinámica política ha demostrado que la gran mayoría de senadores obtienen su votación en sus departamentos de origen. Esta volatilidad del voto en el Quindío es una señal preocupante de la debilidad del vínculo representativo entre los electores y los políticos, que no ha sido corregido por la reforma política.

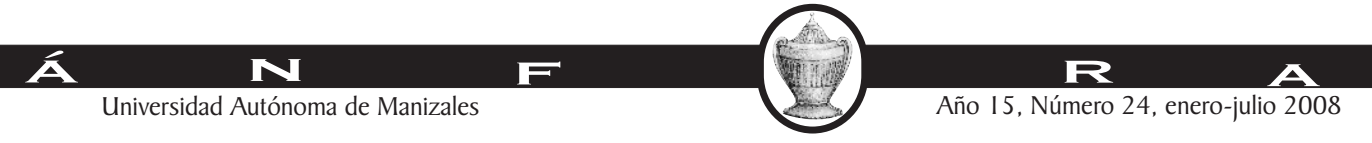




\section{La reforma política de 2003.}

A continuación mostraremos los aspectos más destacados de la reforma política de 2003, los objetivos que se propuso y algunos indicadores para evaluar su impacto en el comportamiento electoral y en el de los actores políticos. La reforma incluye modificaciones al sistema de partidos y modificaciones al sistema electoral. En relación con el sistema de partidos se introduce la exigencia de obtener una votación mínima para que un movimiento o un partido político puedan conservar la personería jurídica, esta votación mínima debe ser de $2 \%$ de los votos válidos en elecciones de Senado y Cámara. Este mecanismo, que se interpreta como una barrera de entrada al sistema político, pretendía inducir un reagrupamiento de los partidos, especialmente obligando a los pequeños movimientos a conformar alianzas para obtener dicho cifra mínima, esto como respuesta a la flexibilidad de la Constitución de 1991 para crear partidos políticos, que permitió el absurdo de identificar cerca de 78 partidos y movimientos políticos registrados ante las autoridades electorales. (Hoyos Gómez, 2007). Otras reformas al régimen de partidos consistieron en la democratización interna para la elección de candidatos, la creación del régimen de bancadas a la hora de la actuación en las corporaciones públicas para inducir más coherencia programática, y reafirmar lo concerniente al financiamiento de las campañas con recursos públicos y el estatuto de la oposición. ${ }^{3}$

En cuanto al funcionamiento del sistema electoral, se introdujeron la lista única, el umbral, la cifra repartidora y el voto preferente, que apuntaban a inducir modificaciones el régimen de la conformación de las candidaturas para corporaciones públicas, el sistema de votación y el sistema de transformación de votos en curules o escaños.

En cuanto al tema de la lista, a partir de la reforma política de 2003, los partidos pueden elegir de entre dos tipos de listas: la lista cerrada y bloqueada, que es la que permitía la Constitución de 1991, en la cual los partidos podían presentar varias listas pues sólo se precisaba de un aval. Esta dispersión de listas, que fue bautizada por el ex Presidente López como "operación avispa", fue una estrategia ganadora en la medida en que se obtenía un mayor número de curules gracias al sistema de cuociente y residuo. Tal y como lo señala Vanegas (2007), esa estrategia le permitió al Partido Liberal presentar 145 listas para
3 Habría que señalar que el acto legislativo que autoriza la reelección inmediata del Presidente de la República se constituye en otra reforma política significativa del sistema político colombiano.

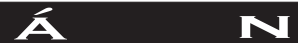

Universidad Autónoma de Manizales 
Senado, obteniendo un total de 29 curules, con el agravante de que sólo fueron elegidos los candidatos cabeza de lista, lo que indica que se trata en realidad de un sistema que esconde un sistema de listas unipersonales sobre la base de liderazgos individuales. En este sistema el partido decide el orden y el elector decide en función de su adhesión partidaria. A partir de la reforma los partidos sólo pueden avalar una lista o un candidato cuando se trate de cargos de elección individual como alcaldes, gobernadores o Presidente.

La reforma política permitió la lista cerrada y no bloqueada, en la cual el elector decide el orden de los candidatos según sus preferencias. Esta posibilidad se concreta con el llamado voto preferente, en el cual el elector, si el partido o el movimiento así lo deciden, elige el candidato dentro del orden no vinculante que propone el partido. El sistema electoral colombiano queda entonces con la posibilidad de lista cerrada y bloqueada, y lista cerrada y no bloqueada ${ }^{4}$ (con voto preferente) que, en la práctica, ha permitido que se reproduzca y refuerce un sistema personalizado de lista, como quiera que los partidos han optado por las listas no bloqueadas, y así cada candidato hace campaña por su nombre. En ese sentido, la lista no bloqueada induce la dispersión política y conspira contra uno de los objetivos centrales de la reforma política, como era el de lograr cierta coherencia y organización. En la medida en que el partido precisa de votos para conseguir el umbral, y el candidato precisa de un aval para poder participar en las elecciones, nos encontramos con lo peor de dos mundos. El partido político así, pierde fuerza doctrinaria en la medida en que lo que importa son las alianzas coyunturales y la suma de votos para sobrevivir. En las elecciones de 2006 se observó el tránsito indiscriminado de candidatos hacia los distintos partidos, sin ninguna coherencia ideológica o programática, de suerte que puede decirse que si bien se logró algo de organización (con el umbral y la lista única), la microempresa electoral como estrategia dominante sigue siendo el común denominador del comportamiento de la mayoría de los actores políticos.

En cuanto al sistema de transformación de votos en escaños, se pasó del sistema de cuocientes y residuos (método Hare), al de la cifra repartidora o método D'Hondt, con el propósito de evitar la fragmentación electoral y la proliferación de listas, e inducir la organización premiando a los partidos más organizados y mayoritarios.
4 La otra posibilidad es la lista abierta en la cual el elector arma su propia lista con candidatos de diferentes partidos.
A N

Universidad Autónoma de Manizales

\section{$\mathbf{R}$}

Año I5, Número 24, enero-julio 2008 
Según el artículo 13 del acto legislativo No, 1 de 2003, "La adjudicación de curules entre los miembros de la respectiva corporación se hará por el sistema de cifra repartidora. Esta resulta de dividir sucesivamente por uno, dos, tres o más el número de votos obtenidos por cada lista, ordenando los resultados en forma decreciente hasta que se obtenga un número total de resultados igual al número de curules a proveer. El resultado menor se llamará cifra repartidora. Cada lista obtendrá tantas curules como veces esté contenida la cifra repartidora en el total de sus votos.

Para obtener la cifra repartidora se ordenan las listas que superaron el umbral de mayor a menor votación, luego se divide cada una de las votaciones por uno, por dos, por tres hasta llegar al número de curules por proveer en la corporación respectiva, luego se ordenan los resultados de mayor a menor, y el último de los resultados que coincida con el número de curules a proveer es la cifra repartidora. Cada una de las votaciones se divide por la cifra repartidora y el resultado es el número de curules a proveer a cada partido. Veamos un ejemplo para la elección de concejales en un municipio donde el concejo tiene 9 escaños y participaron cinco partidos políticos. El partido 1 obtuvo 1800 votos, el partido 2 obtuvo 1600 votos, el partido 3 obtuvo 820 votos, el partido 4 obtuvo 400 votos y el partido 5 obtuvo 200 votos.

\begin{tabular}{|l|l|l|l|l|l|}
\hline & \multicolumn{1}{|c|}{$/ 1$} & \multicolumn{1}{c|}{$/ 2$} & \multicolumn{1}{c|}{$/ 3$} & \multicolumn{1}{c|}{$/ 5$} \\
\hline Partido 1 & 1800 & 900 & 600 & 450 & 360 \\
\hline Partido 2 & 1600 & 800 & 533 & 400 & 320 \\
\hline Partido 3 & 820 & 410 & 273 & 205 & 164 \\
\hline Partido 4 & 400 & 200 & 133 & 100 & 80 \\
\hline Partido 5 & 200 & 100 & 66 & 50 & 40 \\
\hline
\end{tabular}

Como se trata de una corporación con 9 escaños por proveer, se ordenan de mayor a menor los primeros nueve resultados, el noveno resultado es la cifra repartidora. En este caso, 410 es la cifra repartidora.

Luego se divide el total de la votación de cada partido por la cifra repartidora y así se proveen las curules.

Partido 1. 1800/410= cuatro curules

Partido 2. $1600 / 410=$ tres curules

Partido 3. $820 / 410=$ dos curules

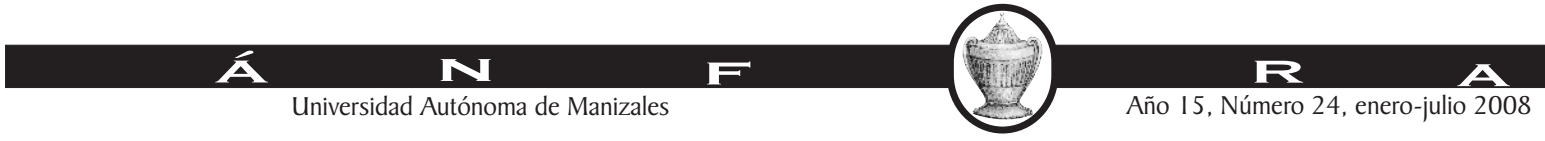


Los otros partidos no obtienen curules. Se entiende que los partidos que sacaron mayor votación, se debe a que lograron hacer alianzas más exitosas., con lo que el método termina castigando a los partidos pequeños y premiando a los partidos más organizados y fuertes.

\section{Un panorama nacional.}

Los resultados de la reforma política han sido ambiguos. Un panorama nacional para las elecciones de Cámara y Senado de 2002 y 2006 nos indican que los objetivos de reducir el número de partidos, fortalecer e institucionalizar las colectividades políticas existentes y elevar la representatividad de las corporaciones públicas, se ha cumplido a medias, en parte por limitaciones introducidas por la propia reforma voto preferente- , y en parte por la enorme capacidad de adaptación de los actores políticos a las nuevas reglas de juego.

\begin{tabular}{|l|c|}
\hline \multicolumn{1}{|c|}{ PARTIDO O MOVIMIENTO POLITICO } & $\begin{array}{c}\text { Curules asignadas en Cámara de } \\
\text { Representantes PARA EL PERÍODO 2006 - } \\
\mathbf{2 0 1 0}\end{array}$ \\
\hline Partido Liberal Colombiano & 35 \\
\hline $\begin{array}{l}\text { Partido Social de Unidad Nacional (partido de la } \\
\text { U) }\end{array}$ & 30 \\
\hline Partido Conservador Colombiano & 29 \\
\hline Cambio Radical & 20 \\
\hline Movimiento Alas-Equipo Colombia & 8 \\
\hline Convergencia Ciudadana & 8 \\
\hline Polo Democrático Alternativo & 8 \\
\hline Apertura Liberal & 5 \\
\hline Movimiento de Integración Regional & 4 \\
\hline Colombia Democrática & 2 \\
\hline Movimiento Huila y Nuevo Liberalismo & 2 \\
\hline Movimiento Nacional & 2 \\
\hline Movimiento Popular Unido & 2 \\
\hline Por el país que soñamos & 2 \\
\hline Afrounincca & 1 \\
\hline Alianza Social Afro colombiana & 1 \\
\hline Mira & 1 \\
\hline Movimiento Moral & 1 \\
\hline Movimiento de Participación Popular & 1 \\
\hline Movimiento de Salvación Nacional & 1 \\
\hline Movimiento Nacional Progresista & 1 \\
\hline Partido de Acción Social & 1 \\
\hline Partido Opción Centro & 1 \\
\hline Fent Giralo y Lopez, 2006 & \\
\hline
\end{tabular}

Fuente: Giraldo y López, 2006

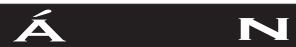

Universidad Autónoma de Manizales

\section{$\mathbf{R}$}

Año I5, Número 24, enero-julio 2008 
Tal vez el efecto más evidente es la reducción de los partidos políticos que lograron conservar su personería jurídica por haber obtenido el umbral para Senado y Cámara. Para Cámara, 23 colectividades obtuvieron curul en 206, frente a las 40 que lo hicieron en 2002, lo que significa una reducción del 41.03\% (Giraldo y López, 2006).

Para Senado, en 2006 sólo diez colectividades obtuvieron curul, además de los dos senadores indígenas de la circunscripción especial, frente a las casi cerca de 40 colectividades distintas, sumando coaliciones, que lo hicieron en 2002.

\begin{tabular}{|l|c|}
\hline \multicolumn{1}{|c|}{ PARTIDO O MOVIMIENTO POLITICO } & $\begin{array}{c}\text { Curules asignadas en Senado para el } \\
\text { periodo 2006 -2010 }\end{array}$ \\
\hline Partido Social de Unidad Nacional (Partido de la U) & 20 \\
\hline Partido Conservador Colombiano & 18 \\
\hline Partido Liberal Colombiano & 18 \\
\hline Cambio Radical & 15 \\
\hline Polo Democrático Alternativo & 10 \\
\hline Convergencia Ciudadana & 7 \\
\hline Movimiento Alas -Equipo Colombia & 5 \\
\hline Colombia Democrática & 3 \\
\hline Mira & 2 \\
\hline Colombia Viva & 2 \\
\hline
\end{tabular}

Fuente. Registraduría Nacional del Estado Civil www.registraduria.gov.co

Esta reducción de partidos y movimientos acercan a Colombia hacia un régimen de pluripartidismo que tiende hacia cinco tendencias ideológicas. Una tendencia estaría liderada por el partido Liberal, otra por el Partido Polo Democrático Alternativo, otra por el Partido Conservador, otros por los partidos de la coalición de gobierno diferentes al Conservador (Cambio Radical, Partido de la $\mathrm{U}$, Convergencia Ciudadana, Colombia Democrática, Colombia Viva, Alas Equipo Colombia) y una última por los movimientos religiosos encabezados por el Mira.

Este reagrupamiento es resultado de las nuevas reglas de juego, pero también de la estrategia política de los partidos en torno de la figura del Presidente de la República. Este reagrupamiento hizo que entre 2002 y 2006, cerca del $40 \%$ de los representantes a la Cámara cambiaran de partido, especialmente hacia Cambio Radical, Partido de la U y Polo Democrático Alternativo que recogió al Frente Social y Político, a la Alianza Ad -M-19, y a otras fuerzas políticas de izquierda ( Giraldo y

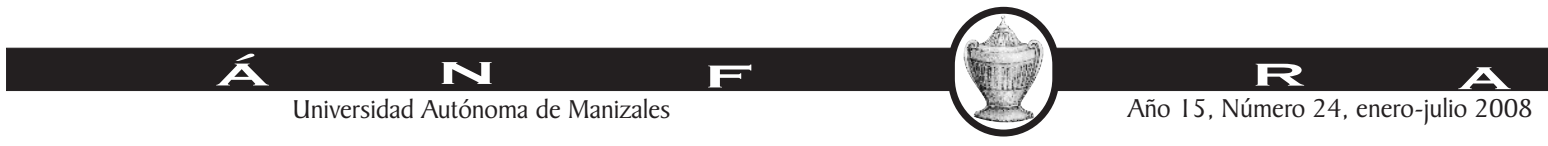


López, 2006). Sin embargo, esta aparente reorganización, contrasta con el hecho de que el método preferido para la conformación de las listas fue el de voto preferente, tanto para Senado y Cámara - para Senado en 2006 sólo el Mira se presentó con lista cerrada y obtuvo curules, y para Cámara, el $84 \%$ de las listas que obtuvieron curul lo hicieron con voto preferente- , con lo que la fórmula personal de lista terminó siendo de nuevo y el objetivo de la institucionalización frente al de personalización quedó en entredicho. En Cámara de Representantes, el $60.8 \%$ de los partidos cuentan con dos o menos representantes, lo que indica, sumado al hecho de que más del $50 \%$ de los partidos actúan en representación de una sola circunscripción, que en esa corporación no existe ningún partido tiene una estructura nacional de representación. Si a ello se suma que de los 23 partidos o movimientos con curul en Cámara, sólo 9 obtuvieron curules en el Senado, nos encontramos ante un escenario de fragmentación, de personalización y de microempresas electorales que contrasta con los objetivos perseguidos por la reforma política de 2003 (Giraldo y López, 2006).

La reagrupación para sobrevivir, fue la nota predominante durante estos cuatro años de implementación de la reforma política de 2003. Y desde el panorama nacional pueden advertirse ciertas tendencias: la consolidación de los grandes partidos, la desaparición de los movimientos ć́vicos y de partidos minoritarios, con lo cual la democracia pierde densidad, la existencia del voto preferente no corrigió el personalismo de la política, y en esa medida no contribuyó a corregir el déficit de representatividad del sistema político. Pero también hay que decir que lo más significativo en estos cuatro años no corrió por cuenta de los cambios en el comportamiento de los actores políticos con ocasión de la reforma política, sino por el hecho de las alianzas de políticos con grupos paramilitares para las elecciones del 2002, lo que ha dado lugar al llamado proceso de la parapolítica, fenómeno que no ha sido ajeno al eje cafetero, Valle y Tolima. Algunos de los políticos vinculados son actores políticos relevantes en Caldas, Risaralda, Tolima y Valle, especialmente. Esta presencia de poderes fácticos en la acción política desborda las pretensiones de este artículo, el cual se concentra en identificar los cambios ocurridos en el comportamiento electoral en el Quindío a partir de la reforma política, pero queremos llamar la atención sobre que no deja de ser un factor que tengamos que considerar como telón de fondo a la hora de hacer una

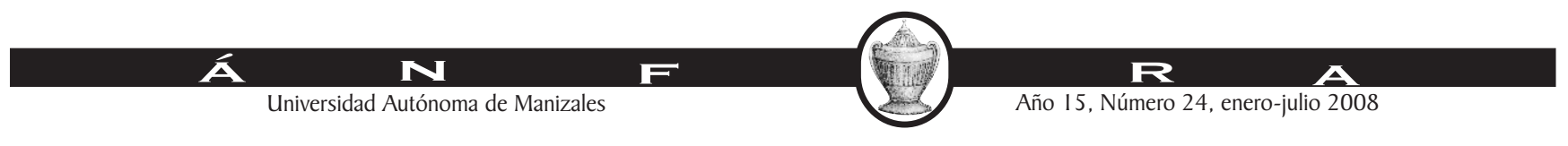


evaluación integral de los cambios en el sistema político y su relación con la legitimidad del régimen político en su conjunto.

\section{Comportamiento electoral en el Quindío ${ }^{5}$}

\subsection{Gobernación.}

En el año 2003, la candidata Amparo Arbeláez Escalante salió elegida como Gobernadora del Departamento del Quindío por el Partido Liberal Colombiano, con de 85,972 votos, que representaron $49.49 \%$ de los votos depositados en las urnas. En segundo lugar, Gildardo Ceballos Zuluaga, representando al Nuevo Partido, con una votación total de 74,400 votos, representando un 43\%. Por último, Carlos Antonio Restrepo Restrepo, por el Movimiento Frente Social y Político, obtuvo 2,283 votos, representando $1.31 \%$ de la votación total.

En el 2007, al menos desde el punto de vista formal, la presencia de los partidos tradicionales no se vio explícita en los candidatos a la Gobernación. El ganador, Julio Cesar Lopez Espinosa, por el movimiento "Por un Quindío para todos", obtuvo un $41.19 \%$ del total de los votos $(94,073)$. Por su parte, Gildardo Ceballos Zuluaga, por el Partido Social de Unidad Nacional "U", obtuvo un $36.33 \%$ de los votos $(82,991)$ y Henry González, del Polo Democrático Alternativo, en tercer lugar, obtuvo 8,250 votos $(3.61 \%)$.

Sin embargo, es claro que el movimiento que elige a López esa el resultado de una estrategia de agrupamiento del partido Liberal Colombiano, el Partido Conservador Colombiano, Alas Equipo Colombia, Colombia Democrática, entre otros. ${ }^{6}$ El Liberalismo, en estricto sentido, conservó la gobernación bajo la orientación del sempiterno cacique liberal Emilio Valencia, sólo que en 2007 se vio en la necesidad de buscar alianzas, y eso puede explicar que incluso haya aumentado la votación. La estrategia del reagrupamiento para conservar el poder se ve clara en las elecciones para gobernador en el Quindío, y el predominio de las fuerzas políticas tradicionales sigue siendo la constante.
5 Toda la información es tomada de la página web de la Registraduría Nacional del Estado Civil www.registraduria.gov.co

6 Para mayor información, c $\quad 0 \quad n \quad s \quad u \quad l \quad t \quad a r$ http://www.juliocesarlope z. com/partidos aliados.php

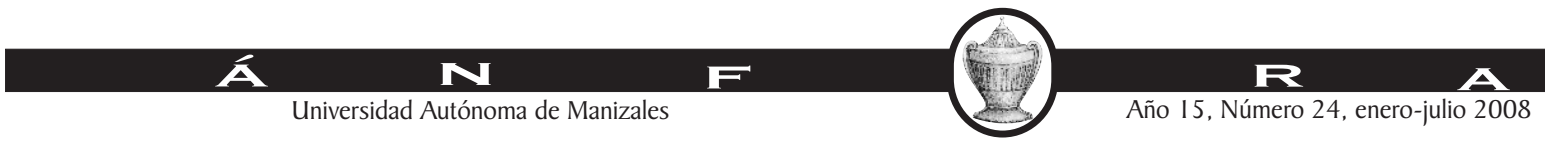




\subsection{Asamblea}

En el 2003, cuatro partidos obtuvieron curules en la Asamblea del Quindío: el Partido Liberal (siete diputados), Nuevo Partido (dos diputados), Partido Conservador (un diputado) y Movimiento Mira (un diputado).

El Partido Liberal obtuvo un 36.65\% de la votación total, con 74,087 votos. Por su parte, el Nuevo Partido obtuvo un 10.01\%, con 20,223 votos, el Partido Conservador, $8.46 \%$ con 17,094 votos y el Movimiento Mira un $5.32 \%$, con 10,743 votos. La mayor votación alcanzada fue la de James Britto Peláez, del Partido Liberal, con 10,490 votos.

En el 2007, la distribución de escaños por partido en la Asamblea el panorama fue el siguiente: El Partido Liberal obtuvo cuatro escaños, Partido Cambio Radical dos y el Movimiento Mira, Partido Conservador Colombiano, Partido Convergencia Ciudadana y Partido Social de Unidad Nacional "Partido de la U", un escaño cada uno.

El Partido Liberal obtuvo 24,290 votos, lo que representa una reducción de $32.79 \%$ de la votación con respecto a las elecciones de 2003; pasó de siete a cuatro diputados. El Movimiento Mira, continuó teniendo un diputado, pero con una reducción importante de número de votos, pasando de 10,743 en 2003 a 4750 en 2007 (44.21\%). El Partido Conservador también sufrió una pérdida importante de votos, pasando de 17,094 votos en el año 2003 a 3477 votos en 2007 (20.34\%), pero conservó su curul en la Asamblea.

La Asamblea se renovó casi en su totalidad, pues sólo Belén Sánchez Cáceres, del Partido Liberal, continuó ocupando una curul. Sin embargo, obtuvo una reducción significativa en términos de votos: pasó de 9,722 votos en 2003 a 4,761 votos en 2007. Todas las listas presentadas para obtener un escaño en la Asamblea del Quindío en el 2007 eran listas con voto preferente.

Lo significativo está en que los partidos tradicionales, el liberal y el conservador, se vieron en la necesidad de compartir el poder con tres nuevas fuerzas políticas: el partido de la U, Cambio Radical y Convergencia Ciudadana. Podría decirse entonces que, salvo la 
confirmación del escaño para el Mira, en la Asamblea del Quindío estamos ante una especie de Frente Nacional ampliado, escenario en el que los partidos tradicionales siguen siendo mayoría, una radiografía de la escasa evolución del sistema político en este departamento. Tanto en gobernación como en Asamblea, la presencia de fuerzas de izquierda u otros movimientos políticos que no hayan tenido origen en los partidos tradicionales es nula, lo que habla acerca de la falta de pluralismo político de la democracia en el Quindío.

\subsection{Alcaldías.}

En el año 2003, Armenia contó con cinco aspirantes a la Alcaldía que representaban diferentes partidos o movimientos. Los candidatos fueron los siguientes: David Barros Gutiérrez, quién fue elegido ganador por el Partido Liberal Colombiano, con una votación total de 38,991 votos (38.25\%); Evelio Henao Ospina, del Partido Conservador, con 21,684 votos (21.27\%); Oscar Gómez Agudelo, del Movimiento Convergencia Ciudadana, con 15,951 votos (15.64\%); Jesús Antonio Niño Sánchez del Movimiento Colombia Viva, con 8,572 votos (8.4\%) y; por último, Edgar Martínez Castillo del Movimiento Frente Social y Político, con 767 votos $(0.75 \%)$.

En el 2007, ninguno de los candidatos que se presentaron en las elecciones locales inmediatamente anteriores, se postuló nuevamente. La ganadora fue Ana María Arango Álvarez, del Partido Cambio Radical, con 56,007 votos (47.41\%), seguida por Luz Piedad Valencia Franco del Partido Liberal, con 34,076 votos (28.84\%). En tercer lugar, Libardo Antonio Taborda Castro del Movimiento Armenia para vivir y crecer, con 8,051 votos, seguido por Bernardo Valencia Cardona del Movimiento Mira con 6,412 votos y Diego Barítica Baena, del Polo Democrático Alternativo, con 2,167 votos. En Armenia, se advierte que Cambio Radical obtiene un importante triunfo, recogiendo el legado del ex alcalde Mario Londoño Arcila. Hoy puede hablarse que en el Quindío nació una nueva fuerza política: el londoñismo, con bastante arraigo popular y con capacidad para derrotar a la propia hija del cacique liberal Emilio Valencia. Este hecho político constituye un importante cambio en la correlación de fuerzas políticas en la ciudad, seguramente jalonado por la adhesión que Cambio radical y el partido de la $U$ tiene respecto de las políticas del Presidente Uribe de gran aceptación en el Quindío.

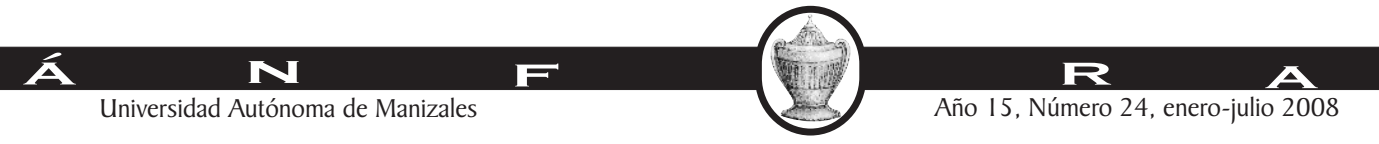


En Buenavista, el Partido Conservador ganó con el candidato Iván Trujillo Arbeláez con un $47.11 \%$ de la votación total. En segundo lugar, Wilfredo Jaramillo Toro, por el Movimiento Nacional, obtuvo un 43.91\% de los votos y por último, Carlos Arturo Gómez Ocampo, del Movimiento Republicano, obtuvo $4.57 \%$ de los votos. En el 2007, el Partido Conservador ganó nuevamente las elecciones, pero con un número menor de votos. Pasó de 751 en el 2003 a 589 en el 2007, que representa un $34.16 \%$ de los votos totales obtenidos. En segundo lugar, el Partido Verde Opción Centro obtuvo 531 votos; en tercer lugar Cambio Radical obtuvo 407 votos. Por último, el Partido de la "U" obtuvo 120 votos. Aquí se confirma el predominio de la política tradicional, especialmente del partido conservador.

En Calarcá, Luz Marllie Alonso Gaviria, por el Movimiento Huella Ciudadana, obtuvo la alcaldía con un $48.63 \%$ de los votos, totalizando 13,206; en segundo lugar, Héctor Faber Giraldo, del Partido Liberal, obtuvo 9,939 votos, representando un $36.6 \%$ del total de votos. En el 2007, el número de candidatos se cuadriplicó, pasando a 8 . El ganador fue Carlos Enrique López Trujillo por el Movimiento Mira, sin duda uno de los hechos más significativos en la política de la segunda ciudad del departamento, con una votación total de 8,129, representando un 26.93\% de los votos totales. En segundo lugar, el Partido de la "U" obtuvo 7,606, con un $25.20 \%$ del total de votos. El Partido Liberal obtuvo 1,152 votos, con un $3.82 \%$, quedando en cuarto lugar. El Movimiento Huella Ciudadana, el cual había ganado la Alcaldía en las elecciones pasadas, no participó en las de 2007. El Partido Colombia Democrática obtuvo 6,815 votos, representando esto un $22.58 \%$. El Polo Democrático Alternativo obtuvo 943 votos con un $3.12 \%$; El Movimiento Apertura Liberal obtuvo 750 votos, con un $2.48 \%$; El Movimiento Nacional Afro colombiano "Afro" obtuvo 680 votos, con $2.25 \%$ de la votación total; el Partido Convergencia Ciudadana, representado por Rigoberto Mora, con 627 votos. El predominio de los partidos tradicionales se erosionó en Calarcá, y supone un cambio importante en el escenario político regional, como quiera que otras fuerzas minoritarias obtuvieran importantes votaciones. El pluralismo político en el Quindío, pasa por Calarcá.

En el 2007, Patricia Mora del Movimiento Circasia Libre obtuvo 6,305 votos, siendo estos, un $52.58 \%$ del total de votos depositados. En

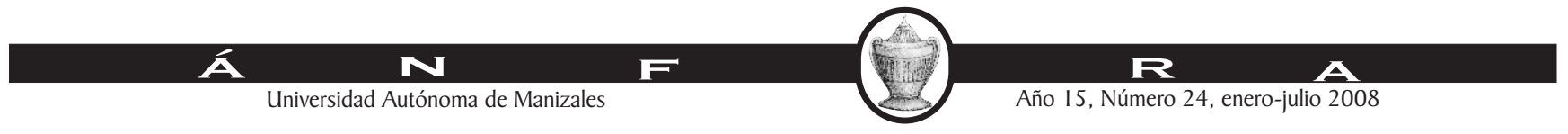


segundo lugar, Mario Restrepo Ocampo del Partido Liberal, obtuvo 4,487 votos, un 37.42\%; en tercer lugar, Javier Antonio Arbeláez por el Polo Democrático Independiente obtuvo 71 votos. ${ }^{7}$ El triunfo de Patricia Mora, con un fuerte arraigo cívico, es una señal interesante de apertura política por fuera de la matriz tradicional de los partidos liberal y conservador. Junto con lo sucedido en Calarcá, es lo más interesante que pasó en las elecciones del 2007 en el Quindío, de cara a la renovación política en el departamento, y a escapar del bipartidismo sin caer en sus franquicias recicladas (Cambio Radical y partido de la U). o en otras etiquetas políticas de dudosa reputación.

En Córdoba, en el 2003, Luz Amparo Jiménez Villarraga, del Partido Liberal Colombiano, obtuvo un $53.7 \%$ de los votos, con 1,356 sufragios. En segundo y tercer lugar, respectivamente, quedaron el Nuevo Partido con 1,005 votos (39.8\%) y el Partido Verde Oxigeno con 51 votos (2.01\%). En las elecciones de 2007, hubo cuatro candidatos: el ganador fue Humberto Turriago Lopez por el Partido Liberal, con 1,330 votos (46.85\%), en segundo lugar, el Partido Cambio Radical obtuvo 1,306 votos (46.00\%); en tercero y cuarto lugar el Movimiento Apertura Liberal y el Partido Conservador Colombiano obtuvieron, respectivamente, 69 y 20 votos. Aquí se confirmó el predominio liberal con el surgimiento de dos nuevas fuerzas políticas: Cambio Radical -que terminó teniendo presencia en prácticamente todo el departamento -

En 2003, en Filandia, Alfonso Londoño Patiño del Partido Conservador obtuvo 2,964 votos (60.41\%) y Jair Morales Jaramillo del Movimiento Político Comunal y Comunitario de Colombia obtuvo 1,567 votos (31.94\%). En el 2007, Simón Morales Jaramillo del Partido de la "U" obtuvo 2,629 votos (47.34\%), seguido por Rosa Elena González del Partido Conservador Colombiano con 1,904 votos (34.29\%) y el Partido Verde Opción Centro con 652 votos (11.74\%). El partido conservador, de larga tradición en Filandia, fue desplazado por el partido de la $U$, lo que confirma el avance de la coalición uribista en el departamento del Quindío como alternativa política.

En el municipio de Génova, en el año 2003, el Movimiento Político Comunal y Comunitario de Colombia obtuvo 1,443 votos (47.81\%), seguido por el Partido Liberal Colombiano con 1,324 votos $(43.87 \%)$ y por el movimiento Unidos por Génova Construiremos Futuro. En el
7 La Registraduría Nacional del Estado Civil no muestra datos para el 2003 para Circasia

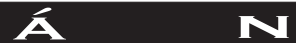

Universidad Autónoma de Manizales

\section{$\mathbf{R}$}

Año I5, Número 24, enero-julio 2008 
2007, el Partido Liberal ganó la Alcaldía con Jhon Didier Grisales, quien obtuvo 2,351 votos $(54.71 \%)$, superando notablemente la votación anterior. En segundo lugar, el movimiento Unidos por Génova Construiremos Futuro superó el número de votos anterior, pues obtuvo 1,251 votos $(29.11 \%)$, seguido por el Partido Verde Opción Centro el cual obtuvo 331 votos (7.70\%), por el movimiento Unidos por una Génova Mejor con 168 votos (3.91\%). Génova, un municipio cordillerano que ha sido escenario de confrontación armada, y que por esa razón ha mostrado graves problemas de gobernabilidad, y además es emblemático en el escenario nacional por ser la cuna de "Manuel Marulanda", fue recuperado por el partido liberal.

En La Tebaida, Maria Edy Segura ganó en el 2003 por el Partido Colombiano con 5,674 votos (46.76\%), seguida del Nuevo Partido con 3,840 votos $(31.64 \%)$ y por el Polo Democrático Independiente con 1,460 votos (12.03\%). En el 2007, Javier Cardona del Partido Liberal obtuvo 8,124 votos (56.22\%), seguido por Maria Teresa Gutiérrez del movimiento Siempre Unidos por la Tebaida con 3,599 votos (24.63\%), por el Partido de la "U" con 1,109 votos (6.97\%) y por el Polo Democrático Independiente con 489 votos (3.35\%). En La Tebaida, el Partido Liberal logró derrotar a las fuerzas cívicas que venían consolidándose desde hace dos períodos, y el Polo Democrático obtuvo la más alta votación en la justa municipal.

En el año 2003, Montenegro eligió a Eleazar Jiménez del Nuevo Partido con 1,231 votos $(46.48 \%)$, seguido por el Partido Colombia Siempre (2,970 votos, $18.04 \%)$, por el Partido Liberal Colombiano (2,789 votos, 16.94\%); en cuarto lugar, el Movimiento Apertura Liberal obtuvo 504 votos $(3.06 \%)$, seguido por el Partido Cambio Radical (452 votos, $2.74 \%$ ). En el 2007, el número de candidatos continuó siendo el mismo. El ganador fue el Partido Cambio Radical, cuya candidata Gloria Inés Gutiérrez Botero obtuvo 6,104 votos (37.02\%), mostrando un aumento muy importante en comparación con las elecciones locales de 2003. En segundo lugar, Jaime Cañas del Partido Liberal obtuvo 5,492 votos también superando la votación pasada. El Partido de la "U" obtuvo 1,445 votos $(8.76 \%)$, seguido por el movimiento Mira (1,331 votos, $8.07 \%$ ) y el Polo Democrático Alternativo (160 votos, $0.97 \%$ ). El Nuevo Partido dio paso a Cambio Radical como sucedió en otros municipios y emergió como una nueva fuerza política.

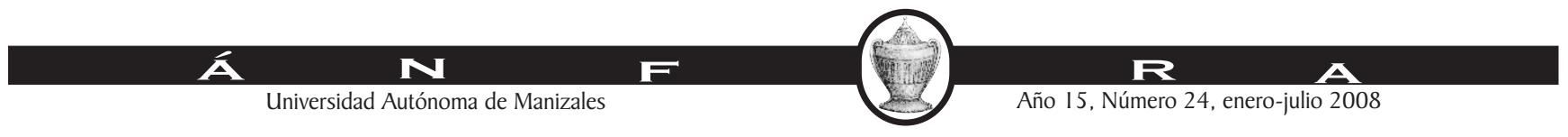


En el municipio de Pijao, las elecciones del 2003 mostraron los siguientes resultados: El Partido Colombia Siempre ganó la Alcaldía con 1,231 votos (43.4\%), seguido por el Partido Liberal el cual obtuvo 821 votos $(28.94 \%)$ y por el Partido Conservador con 655 votos $(23.09 \%)$. En el 2007, el movimiento Unidos por el Progreso de Pijao obtuvo 1,266 votos (34.53\%), seguido por Cambio Radical con 1,196 votos (32.62\%) y el Partido Conservador con 1,071 votos (29.21\%). Fuerzas políticas locales son las que predominan en Pijao, una mezcla de bipartidismo tradicional con algún perfil cívico que le da cierta característica especial frente a otros municipios cordilleranos afectados por el conflicto.

En Quimbaya, en 2007, el ganador fue el movimiento Ciudadanos Solidarios por Quimbaya, con 6,377 votos (40.98\%), seguido por el Partido Liberal con 4,416 votos (28.37\%), por el Movimiento Alianza Social Indígena con 2,504 votos (16.09\%), el Polo Democrático con 264 votos $(1.70 \%)$ y el Partido Convergencia Ciudadana con 92 votos $(0.59 \%){ }^{8}$

Por último, Salento tuvo como ganadora a Laura Bedoya de Gálvis con el Movimiento Con Amor por Salento en el 2003, con una votación de 1,131 votos (38.73\%), seguida por el Partido Liberal con 1,126 votos y por el Partido Conservador, con 540 votos. En el 2007, el Partido Cambio Radical, con Jorge Parra, con 1,644 votos $(44.54 \%)$, seguido por Todos Somos Salento (1,191 votos, 37.27\%), Partido Liberal (376 votos, $10.19 \%)$, por el movimiento Hijos y Amigos de Salento (271 votos, $7.34 \%$ ) y el Partido Colombia Democrática (55 votos, 1.49\%). Este es otro municipio donde los partidos tradicionales se disputan el espacio político con fuerzas cívicas independientes.

\subsection{Concejos $^{9}$}

En las elecciones de 2003, el Concejo de Armenia quedó conformado por 9 miembros del Partido Liberal, con un total de 32,664 votos; por 2 concejales del Nuevo Partido, que obtuvieron 10,482 votos, por dos conservadores, con 8,121 votos, y un concejal de cada uno de los siguientes partidos: Movimiento Político Comunal y Comunitario (4,673 votos), Convergencia Ciudadana (4,530 votos), Movimiento Mira (3,938 votos), Colombia Democrática (3,888 votos), Huella Ciudadana $(3,752$ votos $)$ y Colombia Viva (3,747 votos)
8 Para las elecciones de 2003, la Registraduría no cuenta con información sobre Quimbaya

9 La votación en este punto d e s crit a corresponde a los votos totales obtenidos por cada una de las listas, no por los candidatos ganadores.

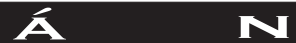

Universidad Autónoma de Manizales
$F$

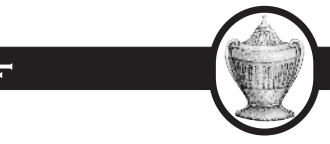

\section{R}

Año I5, Número 24, enero-julio 2008 
En las elecciones de 2007, la composición del Concejo, en términos de repartición de curules por partido, cambió. De las 19 curules disponibles, 5 quedaron en manos del Partido Liberal, cuya lista obtuvo un total de 21,915 votos; 4 en manos de Cambio Radical, con 18,720 votos; 2 de Convergencia Ciudadana, con 8,149 votos en su lista; el Partido de la U obtuvo 2 curules, con 10,851 votos; el Movimiento "Mira" (5,494 votos), Equipo Alas Colombia (4,370 votos), Apertura Liberal (4,255 votos), el Movimiento Nacional Afro colombiano "AFRO" (3,976 votos), Partido Conservador (7,143 votos) y el Partido Verde Opción Centro (5,167 votos), obtuvieron una curul cada uno. Cambio Radical y el Partido de la $U$ aparecen en el escenario político local de la capital del departamento a disputarle el espacio al liberalismo y al conservatismo, junto con otras nuevas fuerzas, lo que hace la composición para Concejo en Armenia una fórmula bastante plural. Puede decirse que en las elecciones para Concejo de 2007, pueden verse las bondades de la reforma política de 2003. Si bien la alcaldesa no tiene mayoría en el concejo, los votos de los partidos de la coalición uribista le garantizan gobernabilidad.

En Buenavista en el 2003, cuatro curules estuvieron ocupadas por miembros del Movimiento Nacional (624 votos), cuatro del Partido Conservador (585 votos) y uno del Partido Liberal (166 votos). Para 2007, el Concejo quedó conformado de la siguiente manera: Cambio Radical, dos curules (384 votos); Verde Opción Centro, dos curules (312 votos); Partido Conservador, una curul (249 votos); Partido Liberal, una curul (301 votos) y Partido de la "U", una curul (210 votos). Se observa una pérdida de espacio político de parte de los partidos tradicionales, lo que obliga a pactos de gobernabilidad impensados antes de la reforma política.

Para Calarcá, en las elecciones de 2003, Huella Ciudadana obtuvo 3 curules (4,671 votos); el Partido Liberal, 3 curules (4,582 votos); el Nuevo Partido, 2 curules (2,612 votos); el Partido Conservador, 2 curules (2,497 votos); Colombia Viva, dos curules (2,390 votos); el Movimiento Mira, una curul (1,755 votos); el Movimiento Político Comunal y Comunitario, una curul (1,661 votos); y el Partido Colombia Siempre, una curul (1,494 votos), en el Concejo del municipio de Calarcá. Para el 2007, el Movimiento Mira aumentó notablemente su participación tanto en número de curules como en número de votos,

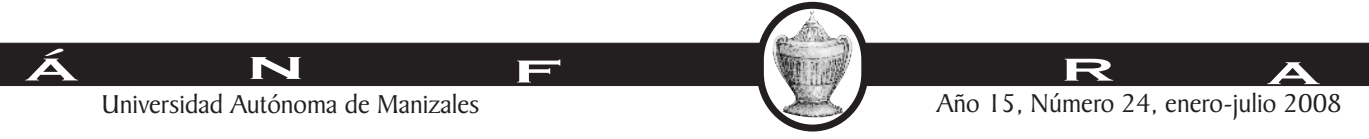


pues pasó a tener 4 curules y 5,234 votos. Colombia Democrática obtuvo 2 curules con 3,071 votos, el Partido Liberal dos curules con 2,652 votos, el Partido de la "U" dos curules con 3,143 votos, Verde Opción Centro dos curules con 2,749 votos, Cambio Radical una curul con 1,492 votos, el Partido Conservador una curul con 1,834 votos y Convergencia Ciudadana una curul con 1,257 votos. Calarcá es el municipio del Quindío donde es más evidente la derrota del bipartidismo tradicional, tanto en alcaldía como en concejo, una señal importante de hacia dónde puede derivar el mapa político en el futuro en todo el departamento.

En Circasia, las elecciones de 2003 estuvieron marcadas por una amplia victoria por parte del Partido Liberal, el cual obtuvo 7 curules de las 13 posibles, con 3,920 votos. Por su parte, el Nuevo Partido obtuvo tres curules con 1,711 votos, el Partido Conservador obtuvo 779 votos, consiguiendo así una curul, al igual que el Movimiento Vamos Colombia (693 votos) y el Movimiento Mira (590 votos). El concejo en el 2007 quedó conformado por 5 miembros del Partido Liberal (3,312 votos), tres de Cambio Radical (1,899 votos), dos de Colombia Democrática (1,291 votos), una del Partido Conservador (912 votos), una de Convergencia Ciudadana (711 votos) y una del Partido de la "U" (953 votos). En Circasia surgen cuatro nuevas fuerzas políticas y el escenario político se hace más plural, el reagrupamiento, pero también la proliferación de listas personales, es un resultado razonablemente atribuible a la reforma política.

El municipio de Córdoba obtuvo los siguientes resultados en 2003: Partido Liberal, 4 curules con 726 votos, Nuevo Partido, 3 curules con 665 votos y Movimiento Político Comunal y Comunitario, dos curules con 362 votos. En el 2007, Cambio Radical obtuvo 3 curules (807 votos), el Partido Liberal obtuvo 3 curules (683 votos), Convergencia Ciudadana, dos curules (474 votos) y el Movimiento Autoridades Indígenas de Colombia una curul (362 votos). Cambio Radical aparece en la escena política disputándole espacio al liberalismo, y tal como sucede en otros municipios, se consolida como una fuerza política capaz de disputarle espacio a los partidos tradicionales. ${ }^{10}$

Filandia, en las elecciones locales de 2003, tuvo cinco representantes de Colombia Democrática (1,645 votos), tres el Partido Conservador
10 Valdría la pena profundizar sobre si los candidatos que aparecen $\mathrm{a} \mathrm{h}$ o $\mathrm{r}$ a c o m o pertenecientes a Cambio Radical pertenecían antes al liberalismo 0 al conservatismo. La hipótesis indica que dados los incentivos de la reforma política, en el Quindío se abrieron paso nuevas fuerzas políticas intérpretes del ideario uribista. Las demandas allí $\mathrm{s}$ a t i s f e cha $\mathrm{s}$ o encontraron respaldo en las fuerzas políticas tradicionales. Es decir, el espacio político en el Quindío se amplió gracias ala reforma política y de la mano del proyecto uribista.

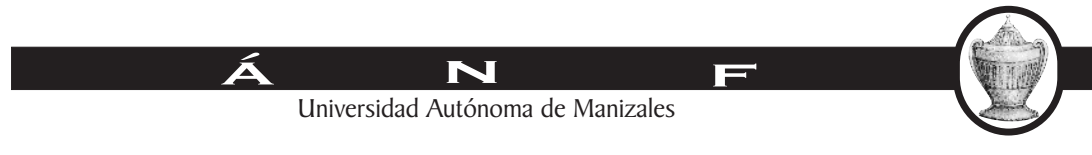


(1,283 votos), dos del Movimiento Político Comunal y Comunitario (671), y uno de Colombia Siempre (342 votos).

En el 2007, Colombia Democrática continuó llevando la delantera, con 5 concejales seguida por el Partido Conservador con 3 concejales, el Partido de la " $U$ " con 2 concejales y Verde Opción Centro con un concejal.

El Concejo del municipio de Génova en el 2003 estaba compuesto por 6 concejales del Partido Liberal (1,110 votos), dos de Apertura Liberal (507 votos), dos del Partido Conservador (439 votos) y uno del Movimiento Republicano (262 votos).

En el 2007, el Partido Liberal perdió un poco de terreno pues sólo alcanzó 3 curules. Apertura Liberal continuó con las mismas 2 curules; Ciudadanos por Génova, el Partido Conservador, Convergencia Ciudadana y Verde Opción Centro obtuvieron cada uno una curul.

En las elecciones de 2003, el Concejo de La Tebaida estaba compuesto de la siguiente manera: Partido Liberal: 5 curules con 3,472 votos; Nuevo Partido, 4 curules con 2,411 votos; Partido Conservador: 2 curules con 1,526 votos; Polo Democrático Alternativo: 1 curul con 1,073 votos; Verde Oxígeno: 1 curul con 612 votos.

En el 2007, el Partido Liberal perdió bastante terreno pues pasó a tener sólo 2 concejales; el Partido Conservador perdió su participación. El Movimiento Colombia Viva obtuvo 2 curules, Cambio Radical 2 curules, Colombia Democrática 2 curules, y una curul respectivamente, los siguientes: Movimiento Mira, Convergencia Ciudadana, Partido de la "U", Verde Opción Centro y Polo Democrático Independiente.

Para Montenegro en las elecciones de 2003 se eligieron concejales de la siguiente forma: Colombia Siempre, 4 concejales (2,535 votos); Partido Liberal, 3 concejales (2,523 votos); Somos Colombia, 3 concejales (2,490 votos); Nuevo Partido, 1 concejal (933 votos); Colombia Democrática, 1 concejal ( 904 votos) y Polo Democrático Alternativo, 1 concejal con 633 votos. En 2007, Cambio Radical obtuvo 4 curules, el Partido Liberal otras 4, el Partido de la U, dos y el Movimiento Mira, Colombia Viva y el Partido Conservador una curul cada

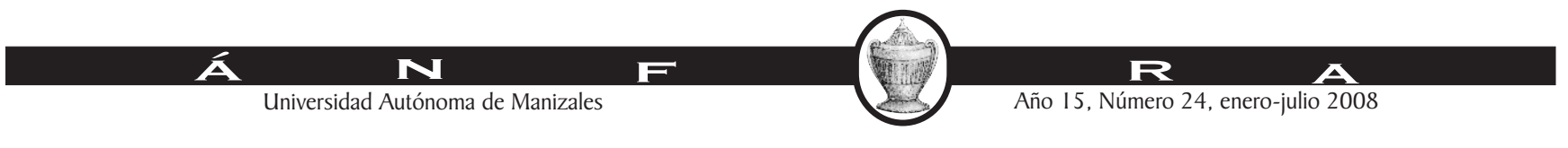


uno. Aquí se refuerza la tendencia de surgimiento de nuevas fuerzas políticas afectas al proyecto uribista en detrimento del predominio tradicional del bipartidismo.

Las elecciones de 2003 en el municipio de Quimbaya mostraron lo siguiente: El Partido Liberal llevó la delantera con 6 concejales y 3,885 votos, seguido por el Partido Conservador con 4 concejales y 2,800 votos. El Nuevo Partido obtuvo 2 concejales con 1,648 votos y Colombia Siempre un concejal con 901 votos. En el 2007, el Partido Liberal obtuvo 4 curules, el Partido Conservador 3 curules, Cambio Radical 2 curules, Colombia Democrática 2 curules, el Partido de la "U" una curul, y Verde Opción Centro una curul. ${ }^{11}$ El surgimiento de nuevas formas de expresión política, cercanas al ideario del gobierno de Uribe, disputándole espacio al liderazgo liberal conservador tradicional, se confirma en Quimbaya

Por último, las elecciones de 2003 en Salento mostraron la siguiente composición del Concejo: Nuevo Partido, 3 concejales y 782 votos; Partido Liberal, tres concejales y 773 votos; Colombia Siempre, 1 concejal y 360 votos; Vamos Colombia, 1 concejal y 293 votos; Apertura Liberal, 1 concejal y 201 votos. En 2007, los resultados fueron los siguientes: Cambio Radical, 3 concejales; Partido Liberal, 2 concejales; Partido de la "U", 2 concejales; Verde Opción Centro, 2 concejales. Como en otros municipios, especialmente el liberalismo perdió espacio político frente a nuevas fuerzas afectas al uribismo.

Puede decirse que el efecto de agrupamiento que indujo la reforma política, y el hecho político del uribismo, fue lo más destacado en el período de aplicación de la reforma política en el Quindío, en cuanto a lecciones locales se refiere.

\subsection{Senado y Cámara de Representantes.}

Si bien la elección para Senado es de circunscripción nacional, es válido hacer el ejercicio sobre si el departamento del Quindío logró o no presencia en la cámara alta en las elecciones 2002 y $2006 . \quad$ Tres candidatos de departamento obtuvieron importantes votaciones pero no lograron los votos requeridos para ser elegidos: el ex gobernador Henry Gómez Tabares del Partido Liberal, con 31.769 votos, Fabio Olmedo Palacio del Movimiento Nueva Fuerza Democrática, con 20.203
11 Las cifras para el municipio de Pijao son inconsistentes.

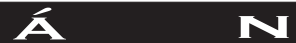

Universidad Autónoma de Manizales
$F$

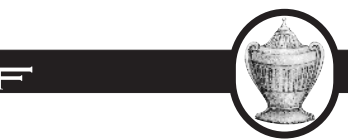

Año I5, Número 24, enero-julio 2008 
votos y Javier Ramírez Mejía de Cambio Radical, con 16811 votos. Llama la atención la gran cantidad de votos que fueron depositados en el Quindío por otros candidatos, un indicador de la volatilidad del voto en el departamento y de la falta de cohesión alrededor de propuestas de actores políticos de la región. De un total de 183.452 votos, 114.669 lo fueron por candidatos "foráneos". En general, se trata de candidatos con muy poca presencia nacional de un departamento con muy poco potencial electoral que se vio afectado por la figura de la circunscripción nacional y en consecuencia, vio disminuida la interlocución del departamento ante el gobierno nacional.

Para el año de 2006, el panorama cambia de manera sustancial, como consecuencia de la reforma política y de la necesidad que tuvieron los candidatos de hacer parte de listas de alcance nacional. Quindío logra, finalmente, elegir dos senadores: el ex alcalde Mario Londoño Arcila por Cambio Radical con 50.095 votos $^{12}$ en el departamento y 53.016 en su votación total; y Ricardo Arias Mora por el partido de la U, con 12.990 votos en el departamento, y 27.315 en su votación total, y quien ingresaría al Senado como consecuencia del retiro de Jairo Enrique Merlano, vinculado al proceso de la parapolítica. Londoño obtuvo prácticamente toda su votación en el Quindío, seguramente como resultado de su gestión como alcalde de Armenia y del impulso que le imprimió el hacer parte de un movimiento político de la coalición uribista, mientras que Ricardo Arias obtuvo una votación importante por fuera del Quindío. El liberalismo y el conservatismo no lograron posicionar ningún candidato para Senado, una señal de desgaste de estas dos colectividades en el departamento, por lo menos en cuanto a representación nacional se refiere.

En relación con Cámara de Representantes, Quindío eligió tres representantes en 2002: Luz Piedad Valencia del Partido Liberal con 48.817 votos, Cesar Augusto Mejía de Equipo Colombia con 26.996 votos y Ricardo Arias de una coalición con 24.053 votos. En 2006, Quindío eligió tres representantes, James Britto del Partido Liberal, con 20.516 votos, una disminución de más del 50\% para el liberalismo en relación con el 2002; Oscar Gómez Agudelo con 11.101 votos de Cambio Radical, ${ }^{13}$ y Héctor Fáber Giraldo del Partido de la $U$, sobre quien no aparece el total de votos obtenidos en la información de la Registraduría. ${ }^{14}$ El Partido Liberal conservó su curul, pero Cambio
12 El senador Mario Londoño Arcila murió en ejercicio de su mandato de una grave enfermedad, y el Quindío "perdió" esa curul.

13 Oscar Gómez fue expulsado de Cambio Radical por faltas a la ética, y hoy ocupa una curul sin pertenecer a ninguna agrupación política. Su labor en el Congreso se ha visto disminuida, gracias a que la ley de bancadas exige que los parlamentarios actúen de manera partidista, lo que en la práctica afecta la calidad de la representación del departamento en esa corporación. Puede decirse entonces que de dos senadores y tres representantes elegidos en 2006, ante la muerte de Mario Londoño, la llegada de Ricardo Arias, y la sanción de Gómez Agudelo, el Quindío tiene un senador y dos representantes y medio, lo que afecta la c a I i d a d d e I a representación.

14 La lista del partido de la U para Cámara en el Quindío, obtuvo 26.687 votos.

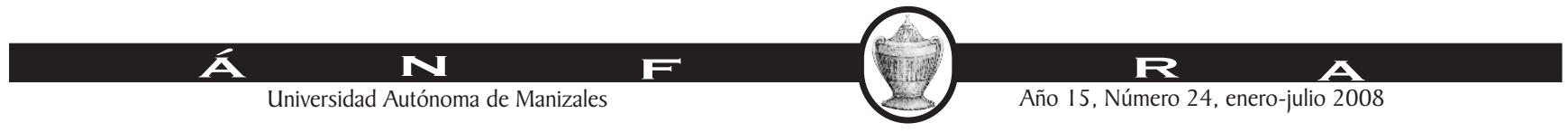


Radical y el Partido de la U obtuvieron representación, sin duda las dos fuerzas políticas beneficiadas por la reforma política en el Quindío. Los movimientos que alcanzaron a tener cierta presencia en las elecciones locales, tales como Convergencia Ciudadana o el Mira, no alcanzaron a tener una representación nacional. La franquicia Cambio Radical y Partido de la U funcionó, lo que hace pensar que, en estos dos partidos, el bipartidismo tradicional se desdobló - como quiera que muchos de sus líderes antes pertenecieran a los partidos tradicionales especialmente en lo que tiene que ver con el Partido Liberal. En el Quindío, dado el comportamiento electoral para Senado y Cámara podríamos estar hablando de una especie de Frente nacional Ampliado, con un Partido Conservador bastante diluido y una presencia bastante marginal del Polo Democrático.

\subsection{Elecciones presidenciales}

En términos de elecciones, el Quindío es mayoritariamente uribista, y esto es coherente con el surgimiento de Cambio Radical y del Partido de la $\mathrm{U}$ - y en menor medida de Convergencia Ciudadana - en el escenario político local. En 2002, Álvaro Uribe obtuvo 126.633 votos, triplicando la votación de Horacio Serpa, quien obtuvo 38.640 votos. Sumados los votos de todos los contendores, Uribe los dobla, lo que da una muestra del poderío del movimiento Primero Colombia. En 2006, Uribe Vélez obtuvo un total de 132.896 votos, ratificando las preferencias de los electores en el Quindío por el proyecto político del político antioqueño. Llama la atención el repunte del Polo Democrático Alternativo que de 9.156 votos con Luis Eduardo Garzón en 2002, pasó a 35.128 votos en 2006 con Carlos Gaviria Díaz, lo que es una señal de que la baja votación de la izquierda en el Quindío tiene que ver más con la falta de buenos candidatos que con una tendencia de rechazo a este tipo de pensamiento político. En el Quindío es claro que Uribe obtiene sus votos sólo, es decir, sin el apoyo de la maquinaria de los partidos y casi como un voto de opinión y de rechazo a la percepción de mala gestión de los dos partidos tradicionales. El voto por Uribe en el Quindío es una señal del declive del bipartidismo, lo que nos ofrece un panorama bastante complejo en términos de coherencia electoral, como quiera que de todos modos, el Partido Liberal especialmente en alcaldías, concejos y Asamblea, conserve un importante poder de representación política. El imaginario de representación en el Quindío, a partir de la reforma

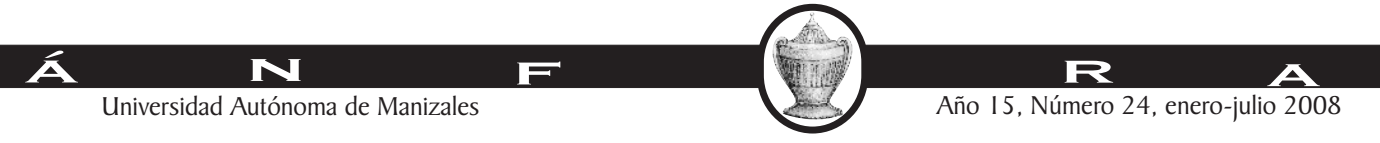


política de 2003, y de la aparición del fenómeno Uribe, se está reconfigurando hacia una suerte de frentenacionalismo ampliado para lo local y de rechazo a los partidos tradicionales hacia lo nacional, una disonancia que es necesario seguir investigando para determinar si esos cambios están mejorando la calidad de la representación política, o si por le contrario ésta se está diluyendo en nuevas aventuras electorales ganadoras en las urnas pero perdedoras a la hora de impulsar la transformación económica y social que demanda un departamento que apenas se recupera de la crisis cafetera, y que a partir del terremoto de 1999 está en un proceso desarticulado de recomposición social, política y de reconversión productiva a la fuerza de las circunstancias.

La presencia del Mira y de Convergencia Ciudadana, y el repunte de Cambio Radical, disputándole espacio al Liberalismo y al Conservatismo, son también una señal de cambio en la estructura social del departamento, como consecuencia, entre otros factores, de los flujos migratorios que se han acentuado a partir del terremoto de 1999, de la mala calidad de las políticas públicas que ha expulsado buen parte de su población productiva hacia el exterior, ${ }^{15}$ y del "descubrimiento de la pobreza", que se ha dado en una región tradicionalmente percibida como ganadora en el contexto del país. La calidad de la política en el Quindío sigue atada a viejas prácticas clientelistas - de las que los nuevos actores políticos no han escapado y, por lo tanto no constituyen una renovación de las costumbres políticas, -, a la captura del Estado representada en que la concesión del negocio del chance sigue siendo el principal botín político por capturar, al menos en el escenario departamental, a la presencia invisible de poderes fácticos ilegales como narcotráfico, paramilitarismo y guerrilla, ${ }^{16}$ que se han asentado territorialmente en zonas donde su influencia se ha hecho sentir, sin que pueda demostrarse dicha influencia de la manera como se ha logrado en los departamentos de la Costa Atlántica, Antioquia, Tolima, Valle del Cauca, Risaralda o Caldas gracias, entre otras razones, a que especialmente narcotraficantes se han mimetizado en actividades comerciales lícitas, y no han gozado del protagonismo y visibilidad que estos actores ilegales han tenido en otras regiones.

En el Quindío el bipartidismo resiste, gracias a viejas prácticas clientelistas, pero sobrevive, no sólo conservando importantes espacios de poder en la gobernación, la Asamblea Departamental, algunas
15 Se calcula que un alto porcentaje de las remesas de los colombianos que viven $y$ trabajan en el exterior se dirigen al departamento del Quindío.

16 La democracia local en Génova, Córdoba, Buenavista y Pijao, y en menor medida en Salento no ha estado ajena a la acción de las FARC. El homicidio del alcalde de Génova para el período 2003-2007, José Heriberto Castro Toro, y de su escolta, fue atribuido al Frente 50 de las FARC. Castro se presentó en 2003 en reemplazo del candidato Jairo Gómez, quien también había sido asesinado. Gustavo de Jesús Arcila, un concejal liberal de Génova que aspiraba a la reelección en octubre de 2007, también fue asesinado, en hecho que las autoridades atribuyen a ese grupo guerrillero con presencia en el Quindío en los límites entre Valle y Tolima en la cordillera central, presencia que fue correspondida con la presencia de grupos paramilitares en la misma zon a d e influencia, escenario de confrontación que sirve de telón de fondo al debate electoral en esos municipios.

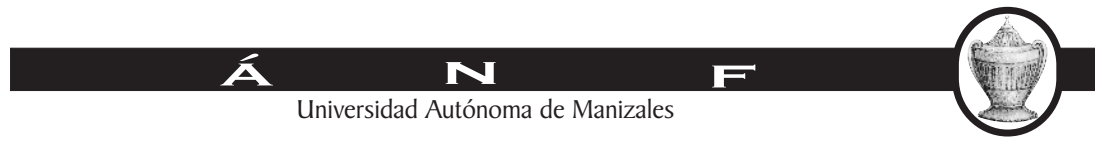


alcaldías y concejos, sino también desdoblándose en nuevos movimientos políticos, en nuevas franquicias como Cambio Radical y el Partido de la $U$ que han recogido el cansancio por la mala calidad de la gestión política del departamento que luego de la crisis cafetera no ha logrado encontrar liderazgos renovadores. Muchos de los dirigentes de los partidos tradicionales, se han trasladado a estas nuevas franquicias, sin que ello suponga necesariamente una mejor representación o un cambio sustancial del mapa político local. No sabemos si esta nueva política es una mejor política y una mejor gestión de lo público.

\section{Bibliografía}

Alcántara Sáez, Manuel. Políticos y política en América latina. Fundación Carolina, Madrid, 2006.

Arango Gaviria, Oscar; Rodríguez Rodríguez, Jahir; Rojas Arias, Miguel Ángel \& Sierra Hernández, Orlando. Democracia, política y paz. Elecciones en el eje cafetero, Editar S.A. La Patria, Manizales, 1998.

Arenas Gómez, Juan Carlos \& Escobar Escobar, Juan Carlos. Un balance de los estudios sobre partidos políticos en Colombia. En, revista Estudios Políticos No. 23, Instituto de Estudios Políticos, universidad de Antioquia, Medellín, julio-diciembre, 2003.

Giraldo, Fernando. Sistema de partidos políticos en Colombia. Estado del arte 1991 -2002. Pontificia Universidad Javeriana, Fundación Konrad Adenauer, Bogotá, 2003.

Giraldo, Fernando \& López José Daniel. El comportamiento electoral y de partidos en los comicios para Cámara de Representantes de 2002 y 2006: un estudio comparado desde la Reforma Política: En, Revista Colombia Internacional, Número 64, Centro de Estudios Internacionales, Departamento de Ciencia Política, Universidad de los Andes, Bogotá, 2006.

Gutiérrez Sanín, Francisco. ¿Lo que el viento se llevó? Los partidos políticos y la democracia en Colombia 1958 -202. Editorial Norma, Colección Vitral, Bogotá, 2007

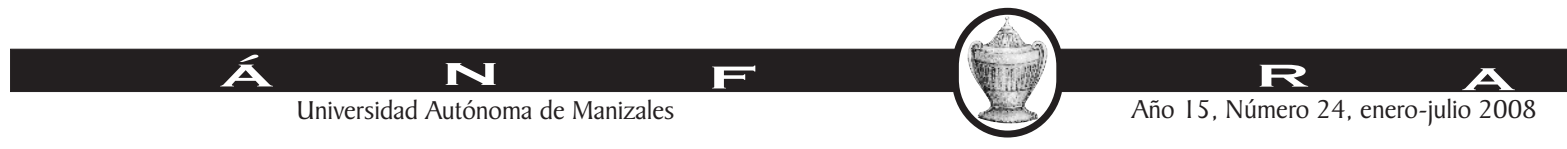


Hoskin, Gary, Masías Núñez, Rodolfo \& García Sánchez, Miguel, compiladores. Colombia 2002. Elecciones, comportamiento electoral y democracia, Universidad de los Andes, Fundación Konrad Adenauer, Registraduría Nacional del Estado Civil y Departamento nacional de Planeación, Bogotá, 2003

Hoskin, Gary \& García Sánchez, Miguel. La reforma política de 2003 ¿La salvación de los partidos colombianos? Universidad de los Andes, CESO, Fundación Konrad Adenauer, Bogotá, 2006.

Hoyos Gómez, Diana. La reforma política de 2003 y su impacto sobre el sistema de partidos. Análisis de las elecciones a Congreso. En, Entre la persistencia y el cambio. Reconfiguración del escenario partidista y electoral en Colombia, Diana Hoyos Gómez, editora académica. Centro de Estudios Políticos e Internacionales, Facultades de Ciencia Política y Gobierno y Relaciones Internacionales, Universidad del Rosario, Bogotá, 2007.

Nohlen, Dieter. Sistema electorales y partidos políticos. Fondo de Cultura Económica, segunda edición, México, 1998.

Pecaut, Daniel. Crónica de dos décadas de política colombiana 1968-

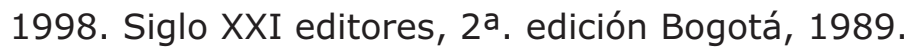

Rodríguez - Raga, Juan Carlos. Cambiar todo para que nada cambie. Representación, sistema electoral y sistema de partidos en Colombia: capacidad de adaptación de las élites políticas a cambios en el entorno institucional. En, Degradación o cambio. Evolución del sistema político colombiano, Francisco Gutiérrez y otros. Editorial Norma, Bogotá, 2002.

Universidad Cooperativa de Colombia. Grupo de investigación, Seccional Medellín, Facultad de Derecho. Incidencia de la reforma política en el sistema electoral y de partidos colombiano, Medellín, 2005.

Valenzuela, Arturo, et ál. Sobre la reforma política en Colombia. Informe de la Consultoría internacional, Georgetown University, Washington, 1999.

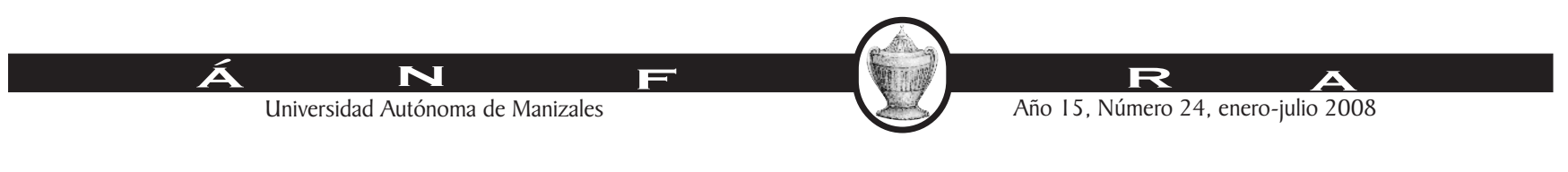


Vanegas Gil, Pedro Pablo. El sistema electoral colombiano en la Constitución de 1991 y sus reformas de 2003 y 2005. En, Estudios de derecho electoral, Universidad Externado de Colombia, Bogotá, 2008. 